\title{
Reactive Impinging-Flow Technique for Polymer-Electrolyte-Fuel-Cell Electrode-Defect Detection
}

\author{
Iryna V. Zenyuk ${ }^{\mathrm{a}, \mathrm{c}}$, Nicholas Englund ${ }^{\mathrm{a}}$, Guido Bender ${ }^{\mathrm{b}}$, Adam Z. Weber ${ }^{\mathrm{a}}$, Michael Ulsh ${ }^{\mathrm{b}, *}$ \\ ${ }^{a}$ Energy Conversion Group, Energy Technologies Area, Lawrence Berkeley National \\ Laboratory, Berkeley, CA 94720, USA \\ ${ }^{b}$ National Renewable Energy Laboratory, Golden, CO 80401, USA \\ ${ }^{c}$ Department of Mechanical Engineering, Tufts University, Medford, MA 02155, USA \\ "Corresponding author. Tel.: +1 303275 3842, e-mail: michael.ulsh@ nrel.gov
}

\begin{abstract}
Reactive impinging flow (RIF) is a novel quality-control method for defect detection (i.e., reduction in Pt catalyst loading) in gas-diffusion electrodes (GDEs) on weblines. The technique uses infrared thermography to detect temperature of a nonflammable $\left(<4 \% \mathrm{H}_{2}\right)$ reactive mixture of $\mathrm{H}_{2} / \mathrm{O}_{2}$ in $\mathrm{N}_{2}$ impinging and reacting on a Pt catalytic surface. In this paper, different GDE size defects (with catalyst-loading reductions of 25, 50, and 100\%) are detected at various webline speeds (3.048 and $9.144 \mathrm{~m} \mathrm{~min}^{-1}$ ) and gas flowrates ( 32.5 or 50 standard $\mathrm{L}$ min ${ }^{1}$ ). Furthermore, a model is developed and validated for the technique, and it is subsequently used to optimize operating conditions and explore the applicability of the technique to a range of defects. The model suggests that increased detection can be achieved by recting more of the impinging $\mathrm{H}_{2}$, which can be accomplished by placing blocking substrates on the top, bottom, or both of the GDE; placing a substrate on both results in a factor of four increase in the $\Delta \mathrm{T}$ (factor of four), which is needed for smaller defect detection. Overall, the RIF technique is shown to be a promising route for in-line, high-speed, large-area detection of GDE defects on moving weblines.
\end{abstract}


Keywords: polymer-electrolyte fuel-cells, reactive impinging flow, quality control, defect detection

\section{Introduction}

The development of the production of membrane-electrode-assembly (MEA) components using roll-to-roll processes [1-4] has resulted in overall polymer-electrolyte-fuel-cell (PEFC) cost reduction and production with improved throughput and repeatability [5, 6]. For continuous processes, such as roll-to-roll, quality control during MEA component manufacturing has been identified as a critical issue [7, 8]. Quality control for the moving two-dimensional functional surface, such as a gas-diffusion electrode (GDE), is challenging because the surface is in continuous motion and because of underlying heterogeneities across the GDE. A GDE sheet consists of a Pt-containing catalyst ink deposited on a porous carbon substrate (i.e. gas diffusion layer (GDL)). As the Pt electrocatalyst is a high-cost contributor to a PEFC stack, maximizing yield during production is of high importance. In addition, uniformity of catalyst-layer (CL) thickness is crucial for optimal PEFC cell performance [9-11]. Moreover, formation of cracks, voids and other mechanical defects in the GDE produced during a high throughput coating process can result in premature cell failure and component degradation [9, 12-14].

Several rapid, nondestructive quality-control techniques are available for in-line defect detection for a GDE fabricated under a continuous process. Optical inspection of visible defects and measurements of coating thickness are used in the PEFC industry [15]. These techniques are limited in their applicability, as not all defects are visible, and offer limited probing depth due to light scattering [16]. More recently, X-ray Fluorescence (XRF) spectroscopy has been applied for measuring GDE Pt loading in-line $[17,18]$. However, XRF is a point measurement, and 
commercial systems are hindered by a slow acquisition time, thus inspecting a full 100\% of GDE area is not feasible in real-time.

Infrared (IR) thermography with active excitation of the GDE material is a nondestructive evaluation tool that allows for complete, rapid, and noncontact defect detection [19-21]. We have demonstrated the feasibility of IR thermography coupled with direct-current (DC) electronicexcitation of catalyst-coated membranes [22] on an industrial-scale webline and reactive-flowthrough (RFT) [23, 24] excitation on stationary, enclosed GDEs. For RFT, a nonflammable (< $4 \% \mathrm{H}_{2}$ ) reactive mixture of $\mathrm{H}_{2} / \mathrm{O}_{2}$ in $\mathrm{N}_{2}$ is flowed through the GDE where the catalytic reaction on the Pt surface generates heat, creating a measurable thermal signature. A proof-of-concept of the extension of the RFT technique to an open-atmosphere environment, where the GDE is conveyed on a bench-top roller system, was previously reported and termed as reactive impinging flow (RIF) [25]. In this work, we report on the further development of the IR thermography technique coupled with RIF to detect defects in moving GDEs. In particular, we describe the transfer of the technique from a bench-top roller system to a research webline both experimentally and theoretically. For the latter, mathematical modeling is used to assess the optimal operation window for defect detection and explore the parameter space. Compared to the prior modeling work of RFT [10], the model developed in this work captures the physics of impinging flow onto the porous GDE on a moving webline. Moreover, this manuscript builds upon RIF technique demonstration [25] and explores optimal parametric space for webline velocity, gas flowrate, composition, and defect geometry for defect detectability. It also provides recommendations for improved defect detection using RIF technique.

The outline of the paper is as follows. First, the experimental setup of the research webline and fabricated GDEs are presented. Then, the model geometric domains, 
approximations, and physics are explained. Model calibration is performed against the thermal response of the pristine GDE on the stationary and moving weblines. Then, the detectability of defects is explored with the experiments and model parametric study. Lastly, methods to increase hydrogen utilization and improve defect detectability is discussed.

\section{Experimental}

The experimental work presented below was performed on an industrial-style roll-to-roll system built by Davis-Standard, which includes unwind and rewind stations to unroll; control speed, tension, and steering; and reroll sheet or roll material. Between the unwind and rewind stations, an experimental station is positioned, whereupon the RIF experimental components and infrared sensor were mounted. The line can handle web material up to $0.46 \mathrm{~m}$ width at speeds of 0.305 to $30.5 \mathrm{~m} \mathrm{~min}^{-1}$ and tensions of 87.6 to $876 \mathrm{~N} \mathrm{~m}^{-1}$. An image of the webline, threaded-up with the GDE sheet fabricated for these experiments, is shown in Fig. 1. 


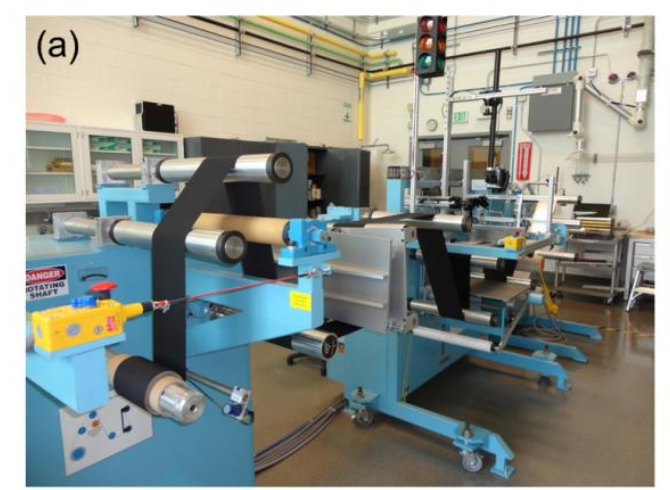

(b)
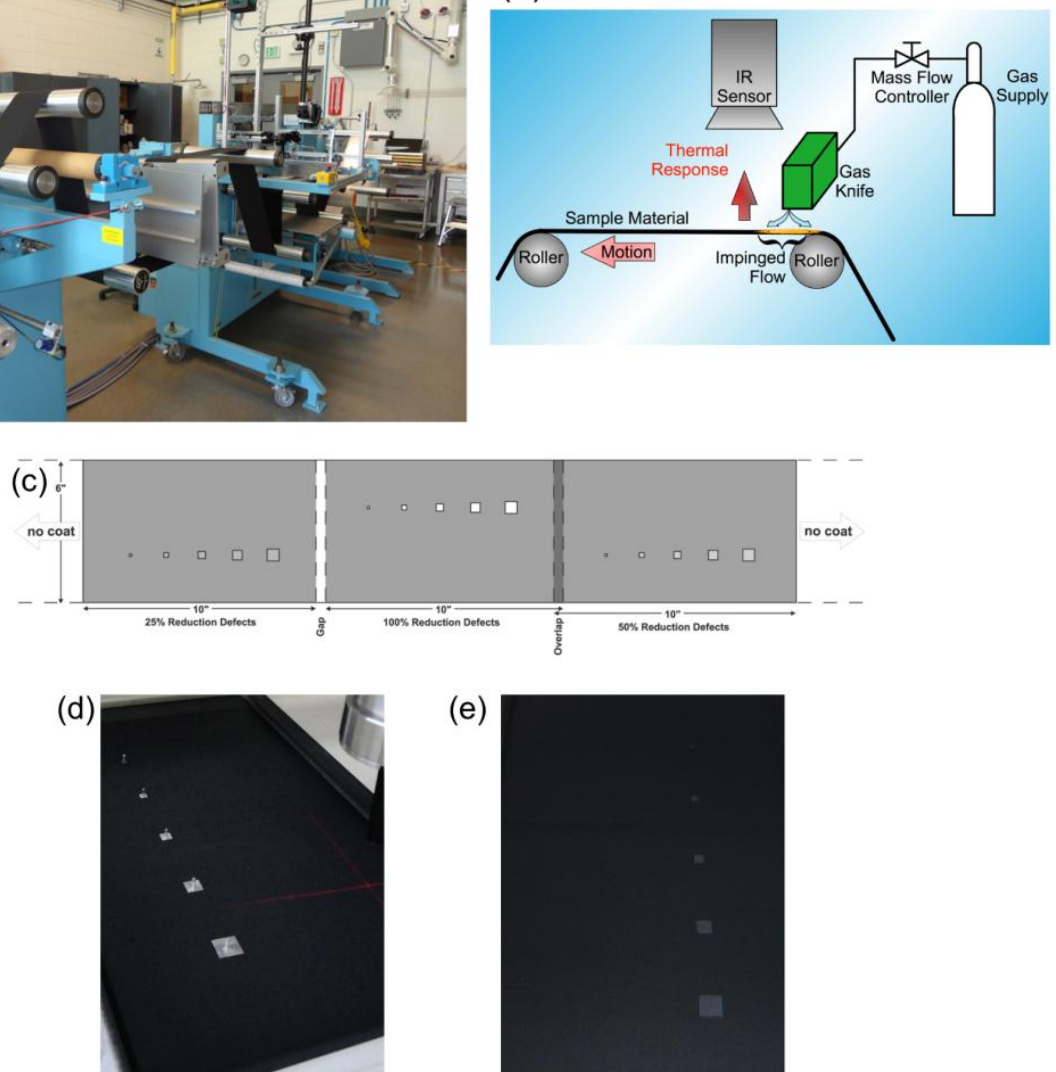

(e)

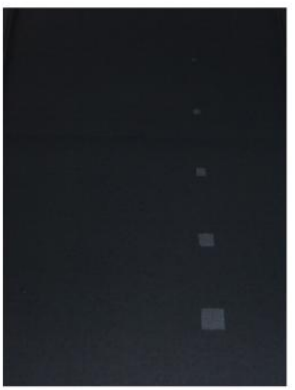

Fig. 1. A) The NREL research webline with GDE sheet. The rewind station is on the front left, the experimental station in the middle, and the unwind on the far right. b) Schematic of the RIF experimental setup. c) Ultrasonically sprayed GDE sample showing three different defect sections that contain five defects each and two different interface sections. d) GDE sample during fabrication showing the five metal masks used for thickness reduction defect creation. e) Section of GDE sample that contains five defects of various sizes featuring $100 \%$ loading reduction.

The GDE sheet was fabricated in-house, such that it contained a variety of CL defects, by spraying Pt-containing catalyst ink onto a GDL substrate. The catalyst ink contained $49.5 \mathrm{wt} \%$ Pt/C catalyst from Tanaka (TKK TEC10E50E), $20 \mathrm{wt} \%$ Nafion ${ }^{\circledR}$ solution with 1100 EW from Ion Power, de-ionized water, and n-propanol. The Nafion ${ }^{\circledR} /$ carbon weight ratio of the ink was adjusted to 0.8. The ink was sprayed onto the substrate using a Sono-tek ExactaCoat spray system with a programmable 3D robotic gantry and a $25 \mathrm{kHz}$ Sono-tek Accumist ultrasonic spray 
head. The nominal loading of the sprayed CL was $0.13 \mathrm{mg}-\mathrm{Pt} \mathrm{cm}^{-2}$. The substrate was an approximately $10 \mathrm{~m}$ long by $0.15 \mathrm{~m}$ wide sheet of GDL with a microporous layer (MPL) coating from AvCarb, LLC (formerly Ballard Material Products). Onto the midsection of the substrate, three successive $0.14 \times 0.25 \mathrm{~m}$ sections of CL were sprayed, each having a different set of defects. Each section had five square defects, of sizes $0.0625,0.13,0.25,0.5$, and $1.0 \mathrm{~cm}^{2}$. In one section, each defect had a $100 \%$ reduction in CL thickness, i.e. each defect was a bare spot. In another section, each defect had a 50\% reduction in the CL thickness. And in the third section, each defect had a $25 \%$ reduction in the CL thickness. Thus, 15 defects were intentionally created of different size and thickness reduction. Fig. 1c shows a diagram of the sprayed section of the GDL sheet. Defects were created by masking the desired defect size during the spray process, as can be seen in Fig. 1d. The desired reduction in thickness was achieved by placing the mask on the surface for the appropriate fraction of the final spray passes, e.g. the last quarter of the passes for a $25 \%$ reduction of CL thickness. Fig. 1e shows an image of the defect sections of the GDE at $100 \% \mathrm{CL}$ reduction. No figure is shown for the $25 \% \mathrm{CL}$ reduction defect section, as the defects were not visible either by eye or optical imaging. The reader can appreciate that CL defects of $<100 \%$ reduction consist of a discrete black area within a black surface, and thus are not easily detected by optical methods.

Fig. 1b provides a schematic diagram of the setup for the RIF webline experiments. Experiments were performed using a non-flammable gas mixture containing $2 \% \mathrm{H}_{2}$ and $1 \% \mathrm{O}_{2}$ in $\mathrm{N}_{2}$. This gas mixture was chosen as a balance between maximizing the thermal response from the $\mathrm{CL}^{[23]}$ and maintaining a safe, i.e. nonflammable, mixture. The gas mixture was delivered from a pressurized gas cylinder to the GDE surface through a gas knife using a bench-top MKS gas-flow-control system. A rectangular stainless steel plenum was used as the gas knife for these 
experiments. The knife had a linear array of laser drilled circular holes of $0.5 \mathrm{~mm}$ diameter with center-to-center spacing of $2 \mathrm{~mm}$ and a total cross-web length of $0.33 \mathrm{~m}$. Reproducible positioning of the gas knife relative to the GDE surface was achieved by using micrometer screws with digital readouts that were integrated into the knife mounting assembly. Alignment of the gas knife relative to the cross-web direction was accomplished by shining light through the holes of the gas knife with a specially designed light source.

During all of the experiments, the GDE was oriented with the CL facing toward the IR camera and impinging gas flow. The operating conditions for the experiments were: (i) gas flowrate of 32.5 or 50 standard $\mathrm{L} \mathrm{min}^{-1}$, (ii) line speed of 3.048 or $9.144 \mathrm{~m} \mathrm{~min}^{-1}$, (iii) substrate tension of $87.6 \mathrm{~N} \mathrm{~m}^{-1}$, and (iv) $1 \mathrm{~mm}$ gas knife height from the GDE surface. The line speed used was intended to reflect current or near-term industry practice with regard to coating PEFC electrodes.

An IR camera (Jenoptik Vario-Cam HiRes) with a 640 by 480 pixel uncooled microbolometer detector was employed to capture the thermal signature of the GDE. The spectral range of the camera was 7.5 to $14 \mu \mathrm{m}$ and its thermal resolution was $0.030 \mathrm{~K}$. The viewing angle of the camera was orthogonal to the substrate. The camera was positioned downstream from the gas knife, relative to the motion of the substrate, at a height above the GDE surface such that the field of view included the gas knife and the excited GDE. IR data collected at a frame rate of 60 frames $\mathrm{s}^{-1}$ were captured with Thermography Suite (IRCameras, Inc.) software. Data consisted of time and temperature information for each pixel recorded with the IR detector. A uniform emissivity of 0.95 was used for the GDE. This value was determined using a comparative method [26] wherein the surface temperature of the GDE measured with the IR 
camera at a set temperature is compared to a material of known emissivity at the same temperature.

\section{Model Formulation}

To guide the experiments, identify optimal conditions of webline velocity and gasmixture flowrate, and explore the limits of the technique relative to not easily experimentally accessible parameter space, a computational model was developed. The model was based on initial work by Das et al. [10] that was developed for stationary, enclosed GDEs. Here, additional fluid-dynamics complexities were included related to the open-atmosphere environment, impinging flow into the porous GDE, and moving webline. Fig. 2a shows a schematic of the model computational domains that include the air and the GDE porous domains (CL, MPL, and GDL). The model is two-dimensional and built to simulate the cross-section of the knife with a gas-flow from a single injection hole, i.e. in the down-web direction, or direction of GDE motion.

The model developed here captures the underlying complex interplay between several mass and thermal processes occurring simultaneously. A sample temperature distribution is depicted in Fig. 2b, where heat generated in the chemical reaction (reaction heat) depends on the impinged hydrogen concentration and temperature, and where convective cooling is a function of impinging flow velocity. The highest generated reaction heat is at the flow impinging point where there is high $\mathrm{H}_{2}$ concentration; however, this point also is the location with the highest impinging gas-flow velocity onto the GDE surface and therefore convective cooling is the highest. Depending on the relative magnitudes between the two heat-transfer phenomena, the 
temperature profile can either have a peak (for low flowrates) or valley (for high flowrates, when convection is significant) at the impingement point.
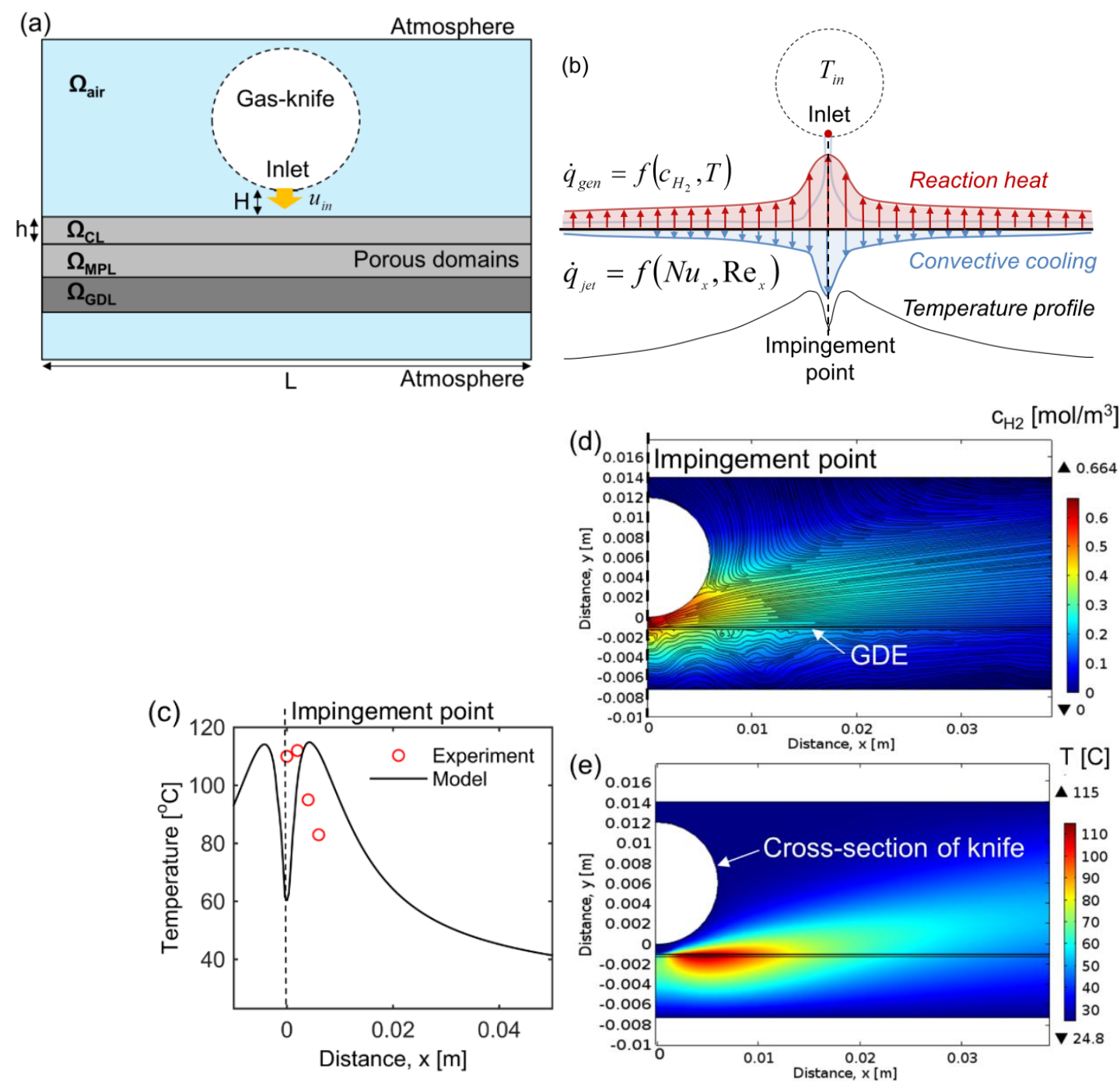

Fig. 2 a) Schematic of the model domains (not to scale) and b) schematic of heat signature of the GDE and a corresponding temperature profile. c) Model temperature profile compared to the experimental data. d) 2D plot of hydrogen concentration with flow streamlines and e) 2D plot of temperature profile.

\subsection{Governing Equations}


The modeled physics are represented with a set of second-order differential equations that include time-dependence, however, here only steady-state solutions are presented. Navier-Stokes and continuity equations describe the flow of gas from the gas-knife that is comprised of a mixture of $2 \% \mathrm{H}_{2}, 1 \% \mathrm{O}_{2}$ and balance nitrogen,

$$
\begin{gathered}
\rho(\boldsymbol{u} \cdot \nabla \boldsymbol{u})=-\nabla P+\nabla \cdot(\mu \nabla \boldsymbol{u})[1] \\
\nabla \cdot(\rho \boldsymbol{u})=0[2]
\end{gathered}
$$

where $\rho, \mu, u$, and $P$ are the gas density, viscosity, velocity, and pressure, respectively.

Continuity with Brinkman's equation are used to describe viscous flow in the porous domains (CL, MPL, and GDL),

$$
\begin{gathered}
\mu \nabla^{2} \boldsymbol{u}-\frac{\mu}{\kappa} \boldsymbol{u}-\nabla P=0 \\
\nabla \cdot(\rho \boldsymbol{u})=0
\end{gathered}
$$

where $\kappa$ is the effective permeability of the porous medium.

To account for $\mathrm{H}_{2}, \mathrm{O}_{2}$ and $\mathrm{N}_{2}$ diffusion, transport of diluted species with convection is applied in air and the porous domains,

$$
\begin{gathered}
\frac{\partial c_{i}}{\partial t}+\nabla \cdot\left(-D_{i, e f f} \nabla c_{i}\right)+\boldsymbol{u} \cdot \nabla c_{i}=R_{i}[5] \\
\boldsymbol{N}_{i}=-D_{i, e f f} \nabla c_{i}+\boldsymbol{u} c_{i}
\end{gathered}
$$

where $c_{i}$ is the molar concentration of species $i, R_{i}$ is a production/consumption term for gas species $i$, and $D_{i, \text { eff }}=\varepsilon^{m} D_{i}$ is the effective gas-phase diffusivity adjusted for porosity and tortuosity in the porous domains, where the Bruggeman coefficients, $m$, for each porous domain are reported in Table 1. 
Table 1. Porous domains properties

\begin{tabular}{|l|l|l|l|}
\hline Parameters & GDL & MPL & CL \\
\hline Length, $\mathrm{L}[\mathrm{mm}]$ & 180 & 180 & 180 \\
\hline Thickness, $\mathrm{h}[\mu \mathrm{m}]$ & 190 & 45 & 9 \\
\hline Porosity & 0.8 & 0.3 & 0.3 \\
\hline Permeability $\left[\mathrm{m}^{2}\right]$ & $1.14 \times 10^{-11}$ & $1.54 \times 10^{-14}$ & $2.3 \times 10^{-15}$ \\
\hline Bruggeman factor, $m$ & $2.2[29]$ & 1.5 & 1.5 \\
\hline
\end{tabular}

The model assumes thermal equilibrium between gas and solid phases. Conservation of energy is used to find the temperature, $T$, distribution,

$$
\left(\rho C_{p}\right)_{e f f} \frac{\partial T}{\partial t}+\rho C_{p} u \cdot \nabla T+\nabla\left(-k_{e f f} \nabla T\right)=r h_{c o m b}[6]
$$

where $C_{p}$ is the specific heat capacity and $k$ is the thermal conductivity. On the right side, the source term is due to the heat generated by chemical reaction, where $h_{\text {comb }}=120\left[\mathrm{MJkg}^{-1}\right]$ is the lower heating value for hydrogen. The effective volumetric heat capacity, $\left(\rho C_{p}\right)_{\text {eff }}$, for the porous domains is a combination of the solid heat capacity, $\left(\rho C_{p}\right)$, and that for gas mixture, $\left(\rho C_{p}\right)_{g}:$

$$
\left(\rho C_{p}\right)_{e f f}=(1-\varepsilon)\left(\rho C_{p}\right)_{s}+\varepsilon\left(\rho C_{p}\right)_{g}[7]
$$

Similarly, the effective thermal conductivity for the porous domains is expressed as

$$
k_{\text {eff }}=(1-\varepsilon) k_{s}+\varepsilon k_{g}[8]
$$

The gas mixture density, specific heat capacity, and thermal conductivity are estimated assuming ideal-gas properties. 
The chemical reaction rate, $r$, is approximated as a one-step combustion reaction of hydrogen and oxygen [27], where the activation energy is assumed to be constant and corresponds to that of a lean flame,

$$
r=A_{v} B c_{H_{2}}^{\alpha} \exp \left(-\frac{E}{R T}\right)[9]
$$

The activation energy, $E$, reaction-rate constant, $B$, hydrogen reaction order, $\alpha$, and a fitting parameter, $A_{v}$, to account for interfacial surface area to volume ratio, are reported in Table 2 [27]. The hydrogen reaction order and $A_{v}$ were adjusted to calibrate the model against the experimental data. A calibration point was chosen from the experimental data for a stationary web and jet velocity of 32.5 standard $\mathrm{L} \min ^{-1}$. Then $\alpha$, and $A_{v}$ were varied to fit the magnitude of temperature peaks and their location.

Table 2. Operating conditions and model parameters.

\begin{tabular}{|l|l|}
\hline Parameters & Value \\
\hline Inlet gas-flow temperature, $T_{i n}[\mathrm{~K}]$ & 298 \\
\hline Inlet pressure (atmospheric in Denver), $P_{i n}, P_{a t m}[\mathrm{~Pa}]$ & 82,000 \\
\hline Molar fraction of inlet hydrogen on percentage basis, $x_{H_{2}, \text { in }}[\%]$ & 2 \\
\hline Molar fraction of inlet oxygen on percentage basis, $x_{O_{2}, \text { in }}[\%]$ & 1 \\
\hline Kinetic rate constant, $B\left[\mathrm{~ms}^{-1}\right]$ & 14 \\
\hline Fitting parameter, $A_{v}\left[\mathrm{~m}^{-1}\right]$ & $1 \times 10^{5}$ \\
\hline Reaction activation energy E $\left[\mathrm{Jmol}^{-1}\right]$ & $14.9 \times 10^{3}$ \\
\hline
\end{tabular}

\subsection{Boundary Conditions}


The modeling air domains were simulated to be sufficiently large such that the horizontal length of the domain was much larger than the diameter of the gas nozzle [28] to represent atmospheric conditions. For the Navier-Stokes equations, the pressure on the outer boundaries of the air domains was set to atmospheric. No-slip boundary condition was applied along the gasknife walls,

$$
u=0 \quad[10]
$$

The velocity of the inlet gas was set to 0 in the $x$-direction and that to the inlet velocity in the $y$-direction. The inlet velocity was computed from the volumetric flowrate through the knife divided by the number of injection holes in the gas-knife and hole area to get velocity per single injection hole. Navier-Stokes equations in the air domains and Brinkman's equations in the porous domains were coupled via boundary conditions on the porous domains through a continuous velocity $y$-direction component:

$$
u_{a i r, y}=u_{p, y}[11]
$$

with the $x$-direction velocity component set to 0 (no-slip) for a stationary web and to the web velocity for a moving webline.

For the dilute-mixture transport equations, a no-flux boundary condition was set at the knife edge. The inlet molar concentrations for oxygen, $c_{\mathrm{O}_{2}}$, hydrogen, $c_{\mathrm{H}_{2}}$, and nitrogen, $c_{N_{2}}$, were specified based on their inlet molar fractions:

$$
\begin{gathered}
c_{\mathrm{H}_{2}}=\frac{x_{\mathrm{H}_{2}, \text { in }} P_{\text {in }}}{N_{A} k T_{\text {in }}} \\
c_{\mathrm{O}_{2}}=\frac{x_{\mathrm{O}_{2}, \text { in }} P_{\text {in }}}{N_{A} k T_{\text {in }}} \\
c_{\mathrm{N}_{2}}=\frac{\left(1-x_{\mathrm{H}_{2}, \text { in }}-x_{\mathrm{O}_{2}, \text { in }}\right) P_{\text {in }}}{N_{A} k T_{\text {in }}}
\end{gathered}
$$


The inlet pressure, $P_{i n}$, and temperature, $T_{i n}$, are reported in Table 2. At the outer boundaries of the air domains, the molar-concentration boundary conditions were set to those of air (i.e., $0 \%$ $\mathrm{H}_{2}, 21 \% \mathrm{O}_{2}, 79 \% \mathrm{~N}_{2}$ ) at atmospheric pressure (in Denver) and temperature.

For the energy-conservation equation, the temperature at the outer boundaries of the air domains was set to atmospheric:

$$
T=T_{\text {atm }}[13]
$$

\subsection{Model Parameters and Numerical Method}

Table 2 reports the model parameters, where the operating conditions were chosen to those of the experimental data. COMSOL Multiphysics 5.1 (COMSOL, Inc., Palo Alto, CA) was used to solve the coupled physics equations with a steady-state solver. The porous domains were meshed with quadrilateral elements, with 600 elements along the $x$-direction and a total number of 15,150 elements. The air domains were meshed with triangular elements, with a total mesh number of 16,755 . Larger mesh density in the porous domains was selected due to their high aspect ratio and also due to high reaction fluxes that can possibly introduce numerical instability. The fully-coupled physics were solved with the direct MUMPS solver.

\subsection{Model validation}

To ensure that the model physics and boundary conditions are implemented correctly and that the mesh density is satisfactory we validated the fluid dynamics computational module against analytical solution. Here we provide salient details, whereas in-depth overview is presented in Supplementary Material. A simplified model with only the fluid-dynamics module was built with COMSOL Multiphysics to model the impinging jet flow, where a stationary and blocking substrate was used instead of the porous GDE. The flow profiles in the three flow 
regions characterizing impinging flow: free jet, impingement, and wall jet regions were validated against reported numerical [28] and analytical [30] solutions for Reynold numbers of $\operatorname{Re}=1$ and $\operatorname{Re}=1000$ (low and high gas flowrates). Excellent agreement was achieved between the model and the solutions reported in the literature for radial and axial flow profiles, shear stresses, and pressures as detailed in S1 section of the Supplementary Material.

\section{Results and Discussion}

\subsection{Application to stationary GDE and model calibration}

As a base-case scenario, a thermal response from a stationary pristine (no defects) GDE on a bench-top roller system was used $[21,25]$. This experiment featured an IR camera angled at 30 degrees to the surface of the GDE to capture the thermal response of the GDE under the knife. The knife was made of a $12.7 \mathrm{~mm}$ diameter stainless steel tube with 115 drilled holes of $0.5 \mathrm{~mm}$ diameter that were spaced $2 \mathrm{~mm}$ apart. The model was calibrated to capture the impinging flow dynamics and thermal response. For the experimental data points shown in Fig. 2c, the temperature was averaged along the GDE at four cross-web locations spaced approximately 2 mm apart.

As Fig. 2c shows, the model captures the experimental trend well - the peak temperature and its location match, and the slope of the temperature decrease away from the impinging point is also similar. However, several model limitations have to be addressed. These include (i) model overestimation of convective cooling immediately under the injection hole because the heat redistribution along the knife in the cross-web direction is not incorporated; and (ii) the kinetic model is simplified and does not incorporate the oxygen dependence in the kinetic rate equation (only through a mass-balance) or adsorbed reaction intermediates or spectators [25]. 
Fig. 2d shows a sample two-dimensional plot of hydrogen concentration and flow streamlines, where the highest hydrogen concentration is at the knife exit and corresponds to $0.66 \mathrm{~mol} \mathrm{~m}^{-3}$. Only half of the modeling domain is shown since, for a stationary web, the flow profile is symmetric about the impinging point. One can observe that a larger portion of hydrogen escapes from the top than permeates/diffuses through the GDE. Fig. 2e shows a twodimensional temperature profile, where a cool spot under the knife is due to convective cooling and the hot spot is shifted to a location of $5 \mathrm{~mm}$ away from the impingement point. It is important to note that the IR-camera captures the temperature signature at the GDE surface, whereas the model calculates the temperature of the GDE and surrounding air.

\subsection{Moving GDEs on a webline}

It is to be expected that cost effective GDE materials will be manufactured on weblines. Fig. 3a shows the experimental thermal response for a pristine GDE moving at a speed of 3.0 $\mathrm{m} \mathrm{min}^{-1}$, through the webline with the gas flowrate of 32.5 standard $\mathrm{L} \mathrm{min}^{-1}$. The location of the knife edge is marked with a black line labeled "y", which also serves as the line along which the 1D thermal profile for Fig. $3 b$ for 32.5 standard $\mathrm{L} \mathrm{min}^{-1}$ is extracted. For accurate defect detection, a uniformity of temperature along the " $y$ " line for pristine GDE is necessary because this temperature serves as a reference temperature for defect detection. From Fig. 3b, for a gas flowrate of 32.5 standard $\mathrm{L} \mathrm{min}^{-1}$, a uniform thermal excitation is observed, whereas, for 50 standard $\mathrm{L} \min ^{-1}$, a less uniform thermal excitation pattern is observed. From the 1D temperature profile shown, it is seen that local thermal fluctuations for the lower flowrate are smaller. To quantify thermal noise associated with the nonuniform temperature profile along the "y" line mean temperature, the standard deviation and noise-to-signal ratio for two gas flowrates and webline velocities are reported in Table 3. To calculate these values, a sample of temperature 
data along the "y" line was taken that encompassed 500 recorded points. For $3 \mathrm{~m} \mathrm{~min}^{-1}$, the mean temperature at a gas flowrate of 32.5 standard $\mathrm{L} \mathrm{min}^{-1}$ was $43.4^{\circ} \mathrm{C}$, whereas that for 50 standard $\mathrm{L} \min ^{-1}$ was $40.7^{\circ} \mathrm{C}$. Standard deviations for temperature profiles for these two gas flow-rates were 1.11 and $1.82^{\circ} \mathrm{C}$, respectively. The noise-to-signal ratio here is defined as two standard deviations divided by the mean temperature. For 32.5 standard $\mathrm{L} \min ^{-1}$ it was $5.12 \%$, however, for 50 standard $\mathrm{L} \mathrm{min}^{-1}$ it was higher at $8.97 \%$.
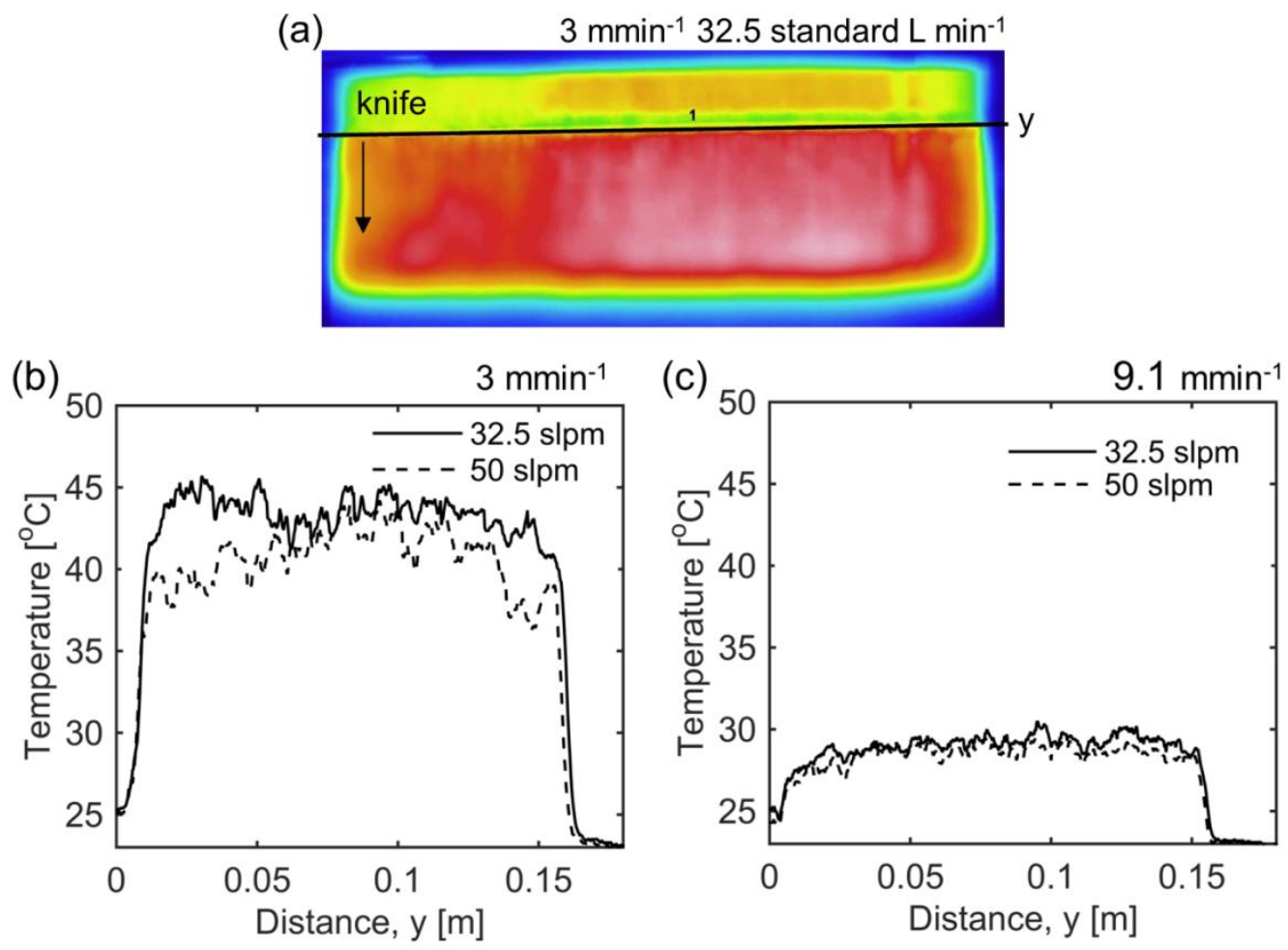

Fig. 3 a) 2D IR thermograph for a webline speed $3.0 \mathrm{~m} \mathrm{~min}^{-1}$, b) cross-sectional 1D plot for webline speed $3.0 \mathrm{~m} \mathrm{~min}-1$ and c) webline speed $9.1 \mathrm{~m} \mathrm{~min}^{-1}$ for gas flow-rates of 32.5 and 50 standard $\mathrm{L} \min ^{-1}$.

Table 3. Statistics for experimental IR thermography data for two webline speeds and two gas flow-rates.

\begin{tabular}{|c|c|c|c|}
\hline Webline speed & Mean temperature, & Standard deviation, & Noise to signal \\
{$\left[\mathrm{m} \mathrm{min}^{-1}\right]$,} & $T_{m}\left[{ }^{\circ} \mathrm{C}\right]$ & $\sigma_{T_{m}}\left[{ }^{\circ} \mathrm{C}\right]$ & percentage, \\
Gas flow-rate & & & $2 \sigma_{T_{m}} T_{m}^{-1} \times 100$ \\
\hline
\end{tabular}




\begin{tabular}{|c|c|c|c|}
\hline$\left[\right.$ standard $\left.\mathrm{L} \mathrm{min}^{-1}\right]$ & & & {$[\%]$} \\
\hline $3.0,32$ & 43.4 & 1.11 & 5.12 \\
\hline $9.1,32$ & 29.0 & 0.79 & 5.42 \\
\hline $3.0,50$ & 40.7 & 1.82 & 8.97 \\
\hline $9.1,50$ & 28.4 & 0.83 & 5.85 \\
\hline
\end{tabular}

For the higher substrate velocity $\left(9.1 \mathrm{~m} \mathrm{~min}^{-1}\right)$, as Fig. $3 \mathrm{c}$ shows, the local temperature fluctuations for gas flowrates of 32.5 and 50 standard $\mathrm{L} \mathrm{min}^{-1}$ were comparable: standard deviations were 0.79 and $0.83^{\circ} \mathrm{C}$, and mean temperatures were 29.0 and $28.4^{\circ} \mathrm{C}$, respectively. The noise-to-signal ratio was very similar for both gas flowrates: 5.42 and 5.85, respectively. Comparing temperature for lower $\left(3.0 \mathrm{~m} \mathrm{~min}^{-1}\right)$ and higher substrate velocity $\left(9.1 \mathrm{~m} \mathrm{~min}^{-1}\right)$, the mean pristine temperature is a factor of 1.6 to 1.7 higher for lower and only 1.1 for higher substrate velocities compared to the ambient temperature. It is desirable to have a higher mean pristine temperature in order to maximize the temperature difference between the pristine and defected locations. However, the tradeoff is that the noise-to-signal on average is larger for higher pristine temperatures. It is worth mentioning that for a stationary GDE, the peak temperature was $118^{\circ} \mathrm{C}$, which is a factor of 4.7 above ambient.

The corresponding model results for the above experimental conditions are shown in Fig. S7 of Supplementary Material. In good agreement with the experimental data, the GDE at a speed of $3.0 \mathrm{~m} \mathrm{~min}^{-1}$ has a higher temperature at the detection point, whereas temperature for higher speed of $9.1 \mathrm{~m} \mathrm{~min}^{-1}$ is lower.

\section{Detection of defects}


Above we only considered instances when a pristine GDE with a nominal loading of 0.13 $\mathrm{mg}_{\mathrm{Pt}} \mathrm{cm}^{-2}$ is either stationary or moving on the webline. In this section, experimental and modeling results are shown for the thermal response of the excited GDEs with defects on a moving webline including parametric studies to identify optimal parameter space for defect detection.

\subsection{GDE Defects on a Moving Webline}

Fig. 4a shows experimental temperature profiles along the width of the GDE for defect areas of 0.125 and $1 \mathrm{~cm}^{2}$ and $100 \%$ loading reduction (i.e. a bare spot) for a web speed of 3.0 $\mathrm{m} \mathrm{min}^{-1}$ and a gas flowrate of 32 standard $\mathrm{L} \mathrm{min}^{-1}$. The position of the center of the defect is shown by the dotted line on the figure. The decrease in temperature, $\Delta \mathrm{T}$, is $18^{\circ} \mathrm{C}$ for the larger defect and $13^{\circ} \mathrm{C}$ for the smaller defect, where $\Delta \mathrm{T}$ is defined as the difference between the mean GDE temperature in the defect-free locations, $T_{m}$, minus the minimum temperature at the defect location, $T_{\text {def }}$ :

$$
\Delta T=T_{m}-T_{\text {def }}(14)
$$

From Table 3 for these operation conditions, the thermal fluctuations due to the signal noise for the pristine GDE are on the order of $+/-1.11{ }^{\circ} \mathrm{C}$. Therefore both 0.125 and $1 \mathrm{~cm}^{2}$ defects are clearly detectable. For the same experimental conditions but $50 \%$ loading reduction $(0.065$

$\mathrm{mg}_{\mathrm{Pt}} \mathrm{cm}^{-2}$ loading), as shown by Fig. $4 \mathrm{~b}$, the $\Delta \mathrm{T}$ is $10{ }^{\circ} \mathrm{C}$ for the larger defect and $8{ }^{\circ} \mathrm{C}$ for the smaller one. These are 1.8 and 1.6 times smaller compared to $\Delta$ Ts for $100 \%$ defect reduction, however still much larger than thermal fluctuations reported in Table 3 and hence detectable. 

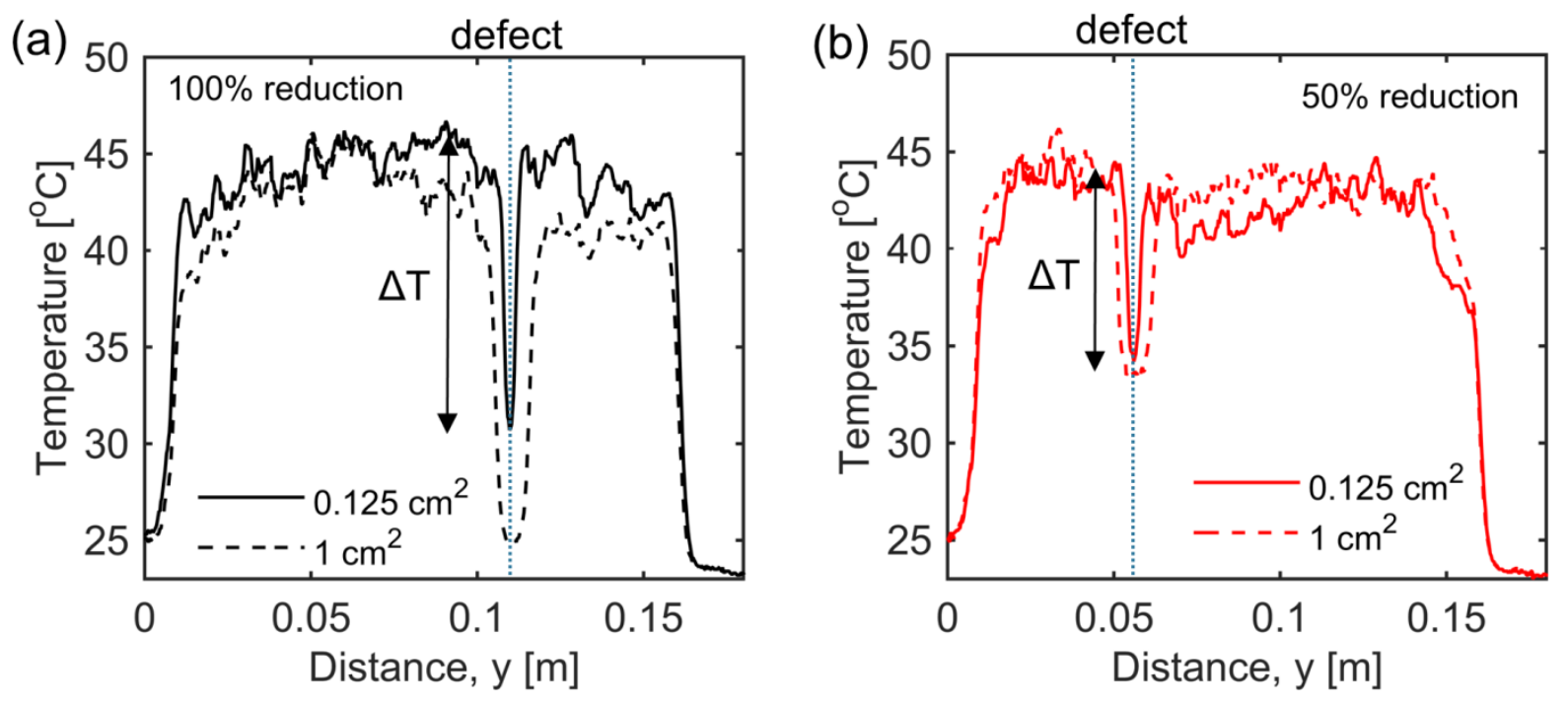

Fig. 4 Temperature profile extracted from IR thermograph for defect areas of 0.125 and $1 \mathrm{~cm}^{2}$ for a) $100 \%$ loading reduction and b) $50 \%$ loading reduction.

It is of interest to explore the limits of defect detectability, which is more effective to do through modeling. Fig. 5a shows $\Delta \mathrm{T}$ as a function of defect width for Pt-loading reductions of 25,50 , and $100 \%$ and webline speed of $3 \mathrm{~m} \mathrm{~min}^{-1}$ and gas flowrate of 32 standard $\mathrm{L} \mathrm{min}{ }^{-1}$. The defect widths are along the down-web dimension and here their cross-web dimension is not considered because the model is not three-dimensional; for simplicity, one may consider them to be squares. A representative detection limit of $1{ }^{\circ} \mathrm{C}$ was chosen for this analysis based on our prior work in developing thermographic inspection methods for fuel-cell materials [22,23]; the actual limit would be set based on signal noise of a fully developed and implemented system. The model results are shown as open symbols and were fit with two linear fits. The filled symbols show experimental data for $\Delta \mathrm{T}$ (as defined by Eq. (14)) of defects, with error bars representing +/- one standard deviation of mean temperature for pristine regions of the GDE in the cross-web direction. As expected, $\Delta \mathrm{T}$ is higher for defects with higher thickness reduction. Two linear regimes are observed for the range of defect widths. For defect widths smaller than 
$0.5 \mathrm{~cm}$, a steep increase in $\Delta \mathrm{T}$ is observed, whereas for defect widths larger than $0.5 \mathrm{~cm}, \Delta \mathrm{T}$ remains approximately constant.
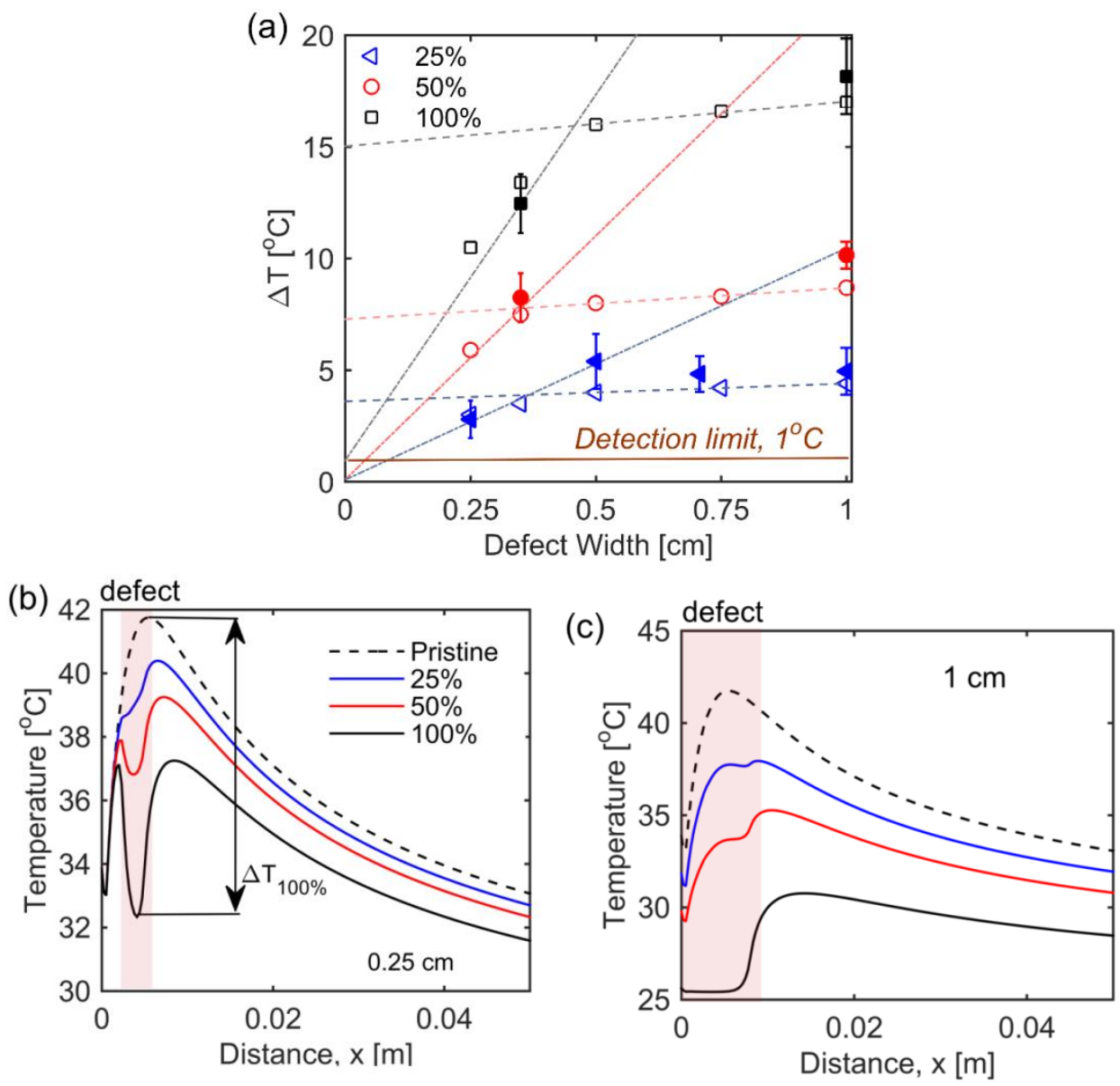

Fig. 5 a) Temperature difference across the defect as a function of defect width for defect reductions of $25 \%, 50 \%$ and $100 \%$ and webline speed of $3 \mathrm{~m} \mathrm{~min}^{-1}$ and gas flowrate of 32 standard $\mathrm{L} \mathrm{min}^{-1}$. Spatial distribution of temperature on top of GDE are shown for b) $0.25 \mathrm{~cm}$ and c) $1 \mathrm{~cm}$ defects, where a pristine (reference) GDE is shown as a dashed line and the defect location is shaded.

For smaller defects, the temperature at the defect midline is higher because of heat conduction from the neighboring pristine regions. As defects become wider, heat conduction to the center of the defect becomes smaller and hence $\Delta \mathrm{T}$ remains approximately constant. For $100 \%$ defect reduction, these two regions are more pronounced, whereas for $25 \%$ reduction, $\Delta \mathrm{T}$ $<5^{\circ} \mathrm{C}$ for the whole range of defect widths. Using the representative detection limit of $1{ }^{\circ} \mathrm{C}$, the 
model predicts that all of the defects at all of the loading reductions studied should be detectable, which is in agreement with the experimental testing. Moreover, the model suggests that the detection limit can be relaxed to $2.5^{\circ} \mathrm{C}$ and the defects will still be detected with this technique. Similarly, the model predicts defect detectability limit of $0.1 \mathrm{~cm}$ defect width or $0.01 \mathrm{~cm}^{2}$ defect area for the conditions in Fig 5a. This defect size is six times smaller than the smallest defect considered in the experimental study, which is indicative that the maximum detection limit of the IR thermography technique has not been reached yet and even smaller defects can be considered in future studies.

Fig. $5 b$ and c show the down-web temperature profile at the GDE surface for 0.25 and $1 \mathrm{~cm}$ defects $\left(0.0625\right.$ and $1 \mathrm{~cm}^{2}$, respectively), which are the smallest and the largest defects tested experimentally. The plotted loading reductions are 25,50 , and $100 \%$, and $\Delta \mathrm{T}$ is the temperature difference defined by Eq. (14). For the modeling study, $T_{m}$ is the temperature for a pristine GDE. The same $\Delta \mathrm{T}$ calculated from Fig. 5b and $\mathrm{c}$ are plotted in Fig. 5a. The locations of the defect are shown as shaded regions. As already shown by Fig. 5a, a much larger variation in $\Delta \mathrm{T}$ is observed for $1 \mathrm{~cm}$ defect compared to $0.25 \mathrm{~cm}$ defect. An interesting observation from the modeling study is that the temperature profile downstream from the defect location is consistently lower than the temperature of a pristine GDE. In the actual experiment, lateral heat conduction and redistribution from the pristine locations should reduce this behavior.

Thus far, only a single operating condition $\left(3 \mathrm{~m} \mathrm{~min}^{-1}\right.$ and 32 standard $\left.\mathrm{L} \min ^{-1}\right)$ has been discussed. However, it is of interest to understand how web speed and impinging gas flowrate affect defect detectability. For this study, six different combinations of web speed and gas flowrates were considered. The web velocities were $3.0,9.1$, and $18.3 \mathrm{~m} \mathrm{~min}^{-1}$, with gas inlet flowrates of 32.5 and 50 standard $\mathrm{L} \mathrm{m}^{-1}$. A very small defect of $0.2 \mathrm{~cm}$ was selected. Fig. $6 \mathrm{a}$ 
shows $\Delta \mathrm{T}$ as a function of $\mathrm{R}$, where $\mathrm{R}$ is defined as the ratio between the web velocity, $\mathrm{u}_{\text {web }}$ and inlet gas flowrate, $\mathrm{V}_{\text {gas }}$. As an example, for the baseline operation condition of $3 \mathrm{~m} \mathrm{~min}^{-1}$ and 32.5 standard $\mathrm{L} \mathrm{m}^{-1}, \mathrm{R}=0.09 \mathrm{~mL}^{-1}$. For each level of $\mathrm{CL}$ reduction, a linear fit was created through the respective modeling data points. Because both flowrate and web velocity were varied, model data points did not fall perfectly onto the linear fit. For three cases of defect loading reduction the slope varied, with steeper slopes for higher defect-loading reductions. This trend is indicative that $\Delta \mathrm{T}$ varies with $\mathrm{R}$ at higher rates for higher defect-loading reduction. For example, for $100 \%$ defect reduction $\Delta \mathrm{T}$ decreased from 8.7 to $4{ }^{\circ} \mathrm{C}$ when $\mathrm{R}$ increased from 0.2 to $0.55 \mathrm{~m} \mathrm{~L}^{-1}$. For the range of $\mathrm{R}$ considered and loading reductions of 50 and $100 \%, \Delta \mathrm{T}$ is always larger than $1^{\circ} \mathrm{C}$. Therefore, if we are only interested in detecting larger defect reductions, such as 50 and $100 \%$, then the web velocity can be as high as $18.3 \mathrm{~m} \mathrm{~min}^{-1}$, a factor of six larger than the baseline scenario. However, for $25 \%$ defect reduction, $\Delta \mathrm{T}$ decreased from $2^{\circ} \mathrm{C}$ at small values of $\mathrm{R}$ to less than $1^{\circ} \mathrm{C}$ at $\mathrm{R}>0.45 \mathrm{~m} \mathrm{~L}^{-1}$. Thus, the model suggests that it will be critical to optimize $\mathrm{R}$ for detection of low-thickness reduction defects.
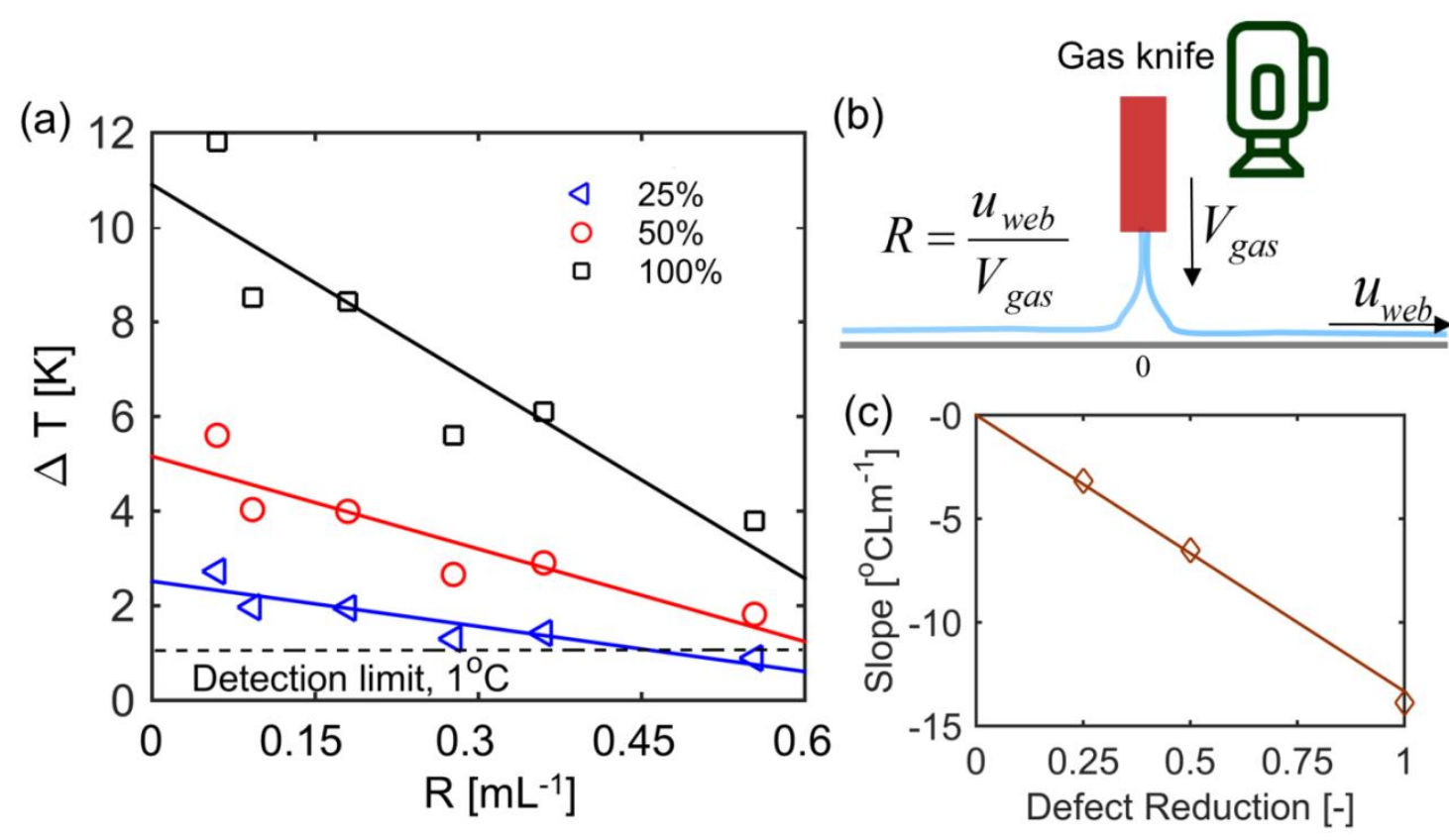
Fig. 6 a) Temperature difference between the pristine and defect $(0.2 \mathrm{~cm})$ locations on the GDE as a function of the ratio of webline velocity to inlet flowrate, $\mathrm{R}$, for three Pt loading reductions: 25,50 and $100 \%$. b) A schematic illustrating the definition of $\mathrm{R}$ and c) slope extracted from a) as a function of defect reduction.

Fig. $6 \mathrm{c}$ plots the slope for $\Delta \mathrm{T}$ vs. $\mathrm{R}$ for each catalyst loading reduction as a function of catalyst loading reduction. For the three defect levels, the slope is linear and becomes more negative for higher loading reductions. Knowing the slope and one model simulation point, the rest of the $\Delta \mathrm{T}$ vs. $\mathrm{R}$ figure can be reproduced, allowing prediction of detectability for any defect at any value of $\mathrm{R}$.

\subsection{Effect of adding a blocking surface and hydrogen utilization}

We look at several improvement strategies to increase $\Delta \mathrm{T}$ and hydrogen utilization by studying the addition of a blocking surface at varying distances on the bottom of the GDE, at a fixed distance of $6 \mathrm{~mm}$ on top and by adding a blocking surface on both top and bottom of the GDE. The results discussed in this section are for the substrate speed of $3.0 \mathrm{~m} \mathrm{~min}^{-1}$ and gas flow-rate of 32 standard $\mathrm{L} \mathrm{min}^{-1}$ and defect size of $5 \mathrm{~mm}$, unless indicated otherwise. 

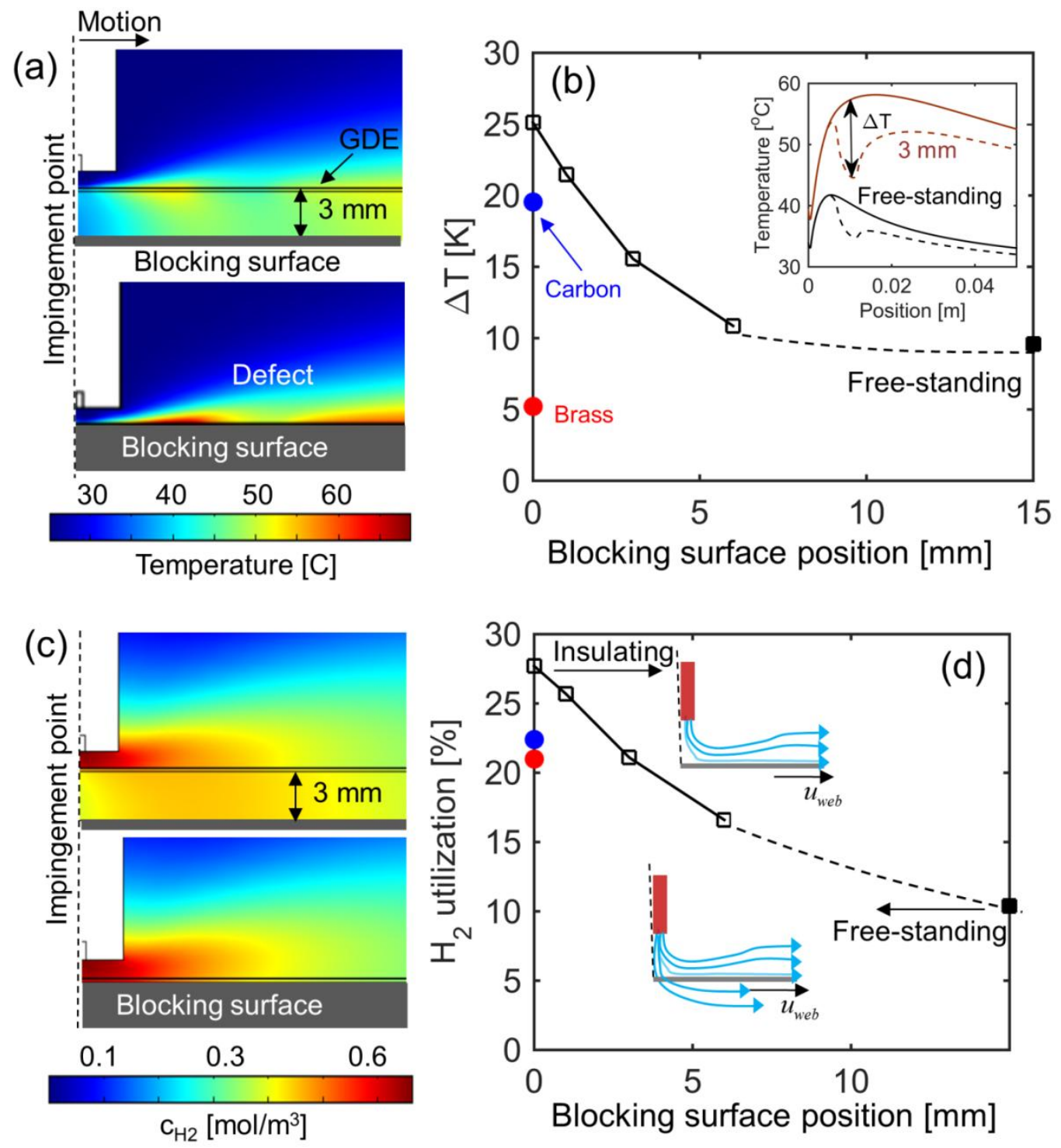

Fig. 7 a) 2D plots of temperature distribution for a webline with a solid surface placed $3 \mathrm{~mm}$ under the GDE and for a GDE with contacting insulating surface. Defect size is $5 \mathrm{~mm}$, GDE speed $3 \mathrm{~m} \mathrm{~min}^{-1}$ and gas flowrate of 32 standard $\mathrm{L} \mathrm{min}^{-1}$. b) Temperature difference between pristine and $5 \mathrm{~mm}$ defect locations as a function of the base position, the brass, carbon bases and free-standing GDEs are shown too. c) 2D plots of hydrogen concentration distributions and d) hydrogen utilization for different substrates and positions.

Fig. 7a shows a two-dimensional temperature distribution for the GDE and surrounding air, where the top plot is for a blocking surface placed $3 \mathrm{~mm}$ under the GDE and the bottom plot is for a blocking surface placed in direct contact with the bottom of the GDE. In the latter 
scenario, the blocking surface is also acting as a perfect heat insulator as shown. To quantify these results and to extend the analysis further, carbon and brass blocking surfaces are also considered in Fig. 7b, where 0 indicates complete contact with the GDE substrate. From this figure, the highest $\Delta \mathrm{T}=25^{\circ} \mathrm{C}$ is for an insulating base and it decreases to $10^{\circ} \mathrm{C}$ for a blocking surface positioned $7 \mathrm{~mm}$ under the GDE; removing the surface even further from the GDE, i.e. creating a "freestanding" GDE layer, does not produce significant changes to $\Delta \mathrm{T}$ as it is far enough away to have no appreciable effect. If, instead of an insulating blocking surface, a blocking material made of carbon or brass is used (i.e., much higher thermal conductivities of 1.7 and $109 \mathrm{~W} \mathrm{~m}^{-1} \mathrm{~K}^{-1}$, respectively), then $\Delta \mathrm{T}$ values of 20 and $5^{\circ} \mathrm{C}$ are observed, respectively, which are 1.25 and 5 times smaller compared to the insulating case.

When the blocking surface is present, $\mathrm{H}_{2}$ is forced to either react within the GDE or escape to the environment at the top as shown by Fig. 7c. Fig. 7d shows the $\mathrm{H}_{2}$ utilization, which is defined as the $\mathrm{H}_{2}$ reaction flux within the GDE divided by the inlet $\mathrm{H}_{2}$ flux. A maximum $\mathrm{H}_{2}$ utilization of $28 \%$ is achieved with the insulating surface and the lowest $\mathrm{H}_{2}$ utilization of $10 \%$ is for the free-standing GDE.

The second improvement strategy considered here is placing a blocking surface $6 \mathrm{~mm}$ above the GDE and the third strategy was placing blocking surfaces on the top and bottom of the GDE, creating a tunnel. Fig. 8a shows the hydrogen distribution and streamlines for a blocking surface $6 \mathrm{~mm}$ above the GDE. The GDE is free-standing and the hydrogen concentration decreases from $0.6 \mathrm{~mol} \mathrm{~m}^{-3}$ near the impingement point to close to 0 underneath the GDE. Fig. 8a (bottom 2D image) shows the hydrogen concentration when an additional blocking substrate is introduced at the bottom of the GDE. The hydrogen concentrations in air above the GDEs for both studied cases are similar; however, a major difference is observed in the hydrogen 
concentration at the reacting layer as shown in the zoomed-in images. For the free-standing GDE, the hydrogen concentration rapidly drops within the GDE, whereas, for the GDE / blocking surface case, the hydrogen concentration remains constant through the GDE thickness in the location under the impingement point. From Fig. 8b, having the blocking surface on top of GDE produced a higher $\Delta \mathrm{T}$ at $\mathrm{R}<0.2 \mathrm{~m} \mathrm{~L}^{-1}$, however, no significant difference in $\Delta \mathrm{T}$ was observed at $\mathrm{R}>0.2 \mathrm{~m} \mathrm{~L}^{-1}$. More than a four-fold increase in $\Delta \mathrm{T}$ is observed for the case of the GDE having both top and bottom blocking surfaces (a tunnel) for a full range of R.
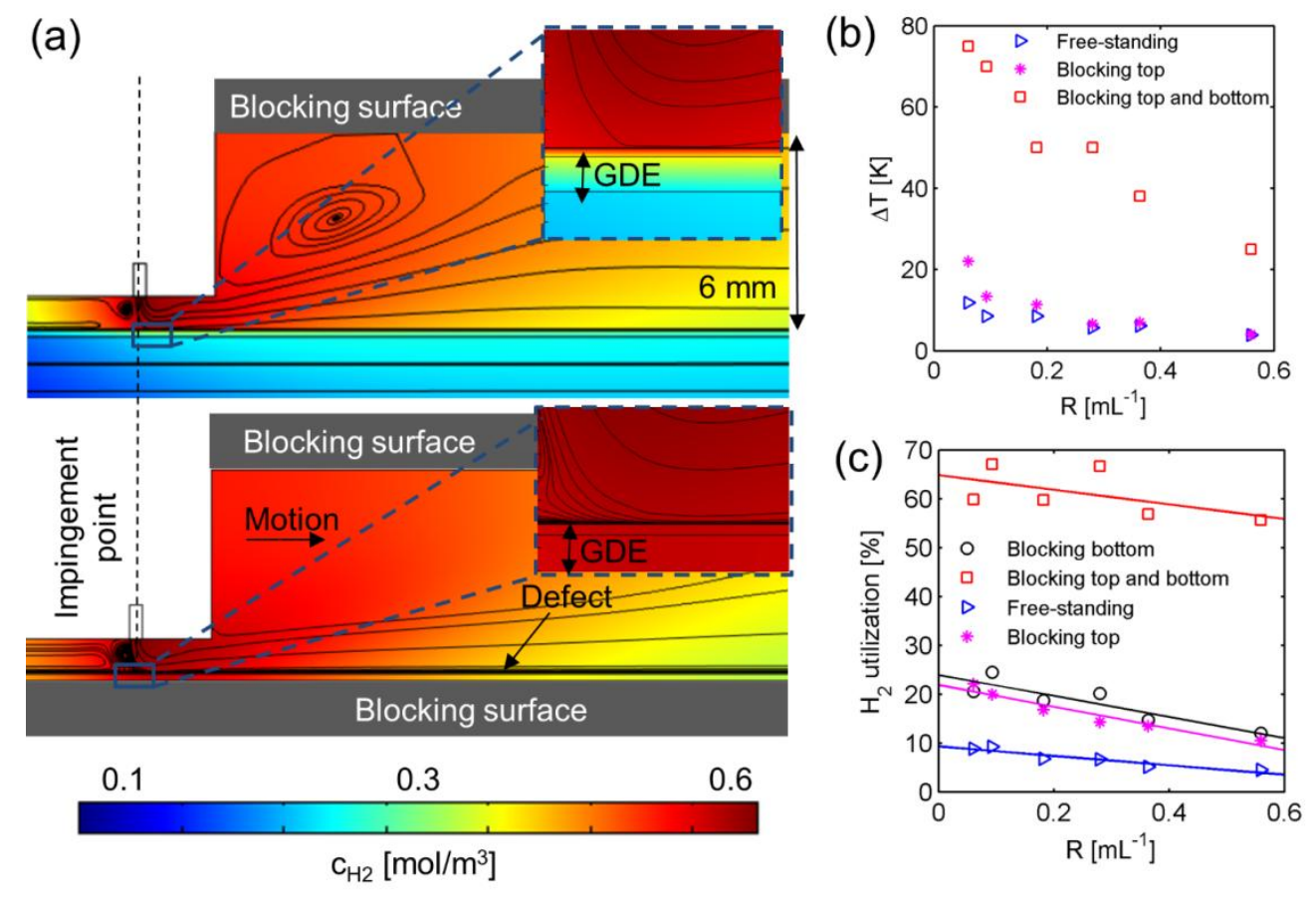

Fig. 8 a) 2D plots of hydrogen concentration distribution for a webline GDE speed of $3 \mathrm{~m} \mathrm{~min}^{-1}$ and gas flowrate of 32 standard $\mathrm{L} \mathrm{min}^{-1}$ with a blocking surface on the top (top image) and both top and bottom (bottom image). b) $\Delta \mathrm{T}$ as a function of $\mathrm{R}$ for free-standing, blocking top, and blocking top and bottom cases. c) Hydrogen utilization as a function of $\mathrm{R}$ for free-standing GDE, with the solid base on the top and with the solid base on the bottom and $6 \mathrm{~mm}$ above the GDE.

Practically, to utilize a blocking surface on the top of the GDE on the webline might be challenging because it can interfere with the thermal signal for IR detection. A slit opening in the 
solid surface or an IR-transparent material for the blocking surface are two possible solutions to ensure that the surfaces are blocking and that the IR-camera can detect the GDE's thermal response. As for the surface on the bottom of the GDE, a similar solution to the one discussed in the section above can be utilized.

\section{Conclusion}

Reactive impinging flow (RIF) of a $\mathrm{H}_{2} / \mathrm{O}_{2} / \mathrm{N}_{2}$ gas mixture was used to excite $\mathrm{Pt}$ electrocatalysts thermally within a gas-diffusion electrode (GDE) for in-line quality-control detection using infrared (IR) thermography. The RIF setup was implemented on a research webline, where 15 GDE defects of sizes $0.0625,0.13,0.25,0.5$, and $1.0 \mathrm{~cm}^{2}$ and catalyst loading reductions of 25,50 and $100 \%$ were successfully detected at different webline speeds and gas flowrates. Mathematical modeling was conducted to identify detection limits for different web velocity and gas flowrate as a function of defect size. For a detection threshold of $1{ }^{\circ} \mathrm{C}$, the model correctly predicted that all of the experimentally studied defects should be detectable with the RIF technique. Moreover, the model predicted that much smaller defects can be detected under certain operating conditions.

A modeling study was used to design several improvement routes to achieve an even larger defect detection window and higher utilization of $\mathrm{H}_{2}$ from the impinging stream. It was shown that placing a blocking substrate on top $(6 \mathrm{~mm})$ or at various distances below the GDE increased $\Delta \mathrm{T}$ and hydrogen utilization. Substrates with various thermal conductivities were studied and it was found that an ideal insulator produces the largest $\Delta \mathrm{T}$, whereas a blocking surface that acts as a strong heat sink lowers the $\Delta$ Ts with respect to a free-standing GDE. However, the most dramatic increase in $\Delta \mathrm{T}$ (factor of four) was achieved by placing blocking 
surfaces on both the top and bottom of the GDE, creating a hydrogen tunnel due to the higher hydrogen concentrations sustained within the GDE in this scenario. Future studies will explore experimentally the use of a blocking substrate that is impermeable to hydrogen to validate model predictions. Overall, the RIF technique is shown to be a promising route for in-line, high-speed, large-area detection of GDE defects on moving weblines.

\section{Acknowledgments}

The authors acknowledge funding for this work provided by the Fuel Cell Technologies Office, of the U. S. Department of Energy, Energy Efficiency and Renewable Energy under contract numbers DE-AC36-08-GO28308 (NREL) and DE-AC02-05CH11231 (LBNL), Program Manager Nancy Garland. 


\section{References}

[1] M.K. Debe, Nature, 486 (2012) 43-51.

[2] D.E. Curtin, R.D. Lousenberg, T.J. Henry, P.C. Tangeman, M.E. Tisack, Journal of Power Sources, 131 (2004) 41-48.

[3] R.R. Søndergaard, M. Hösel, F.C. Krebs, Journal of Polymer Science Part B: Polymer Physics, 51 (2012) 16-34.

[4] T. Steenberg, H.A. Hjuler, C. Terkelsen, M.T.R. Sanchez, L.N. Cleemann, F.C. Krebs, Energy \& Environmental Science, 5 (2012) 6076-6080.

[5] V. Mehta, J.S. Cooper, Journal of Power Sources, 114 (2003) 32-53.

[6] F. Barbir, S. Yazici, Int J Energ Res, 32 (2008) 369-378.

[7] in, ACI,Inc., 2012.

[8] R.J. Balliet, J. Newman, J Electrochem Soc, 158 (2011) B927.

[9] A.Z. Weber, J. Newman, Journal of The Electrochemical Society, 154 (2007) B405-B412.

[10] P.K. Das, X. Li, Z.S. Liu, Journal of Electroanalytical Chemistry, 604 (2007) 72-90.

[11] A.A. Kulikovsky, International Journal of Hydrogen Energy, 36 (2011) 4449-4453.

[12] R. Borup, J. Meyers, B. Pivovar, Y.S. Kim, R. Mukundan, N. Garland, D. Myers, M.

Wilson, F. Garzon, D. Wood, P. Zelenay, K. More, K. Stroh, T. Zawodzinski, J. Boncella, J.E.

McGrath, M. Inaba, K. Miyatake, M. Hori, K. Ota, Z. Ogumi, S. Miyata, A. Nishikata, Z.

Siroma, Y. Uchimoto, K. Yasuda, K.-i. Kimijima, N. Iwashita, Chemical Reviews, 107 (2007) 3904-3951.

[13] A.Z. Weber, J. Newman, Journal of The Electrochemical Society, 153 (2006) A2205A2214. 
[14] M. Pestrak, Y. Li, S.W. Case, D.A. Dillard, M.W. Ellis, Y.-H. Lai, C.S. Gittleman, Journal of Fuel Cell Science and Technology, 7 (2010) 041009-041009.

[15] S. Couse, T. Akin, in, Google Patents, 2014.

[16] R. Su, M. Kirillin, E.W. Chang, E. Sergeeva, S.H. Yun, L. Mattsson, Opt. Express, 22 (2014) 15804-15819.

[17] C. Wyon, D. Delille, J.P. Gonchond, F. Heider, L. Kwakman, S. Marthon, I. Mazor, A. Michallet, D. Muyard, L. Perino-Gallice, J.C. Royer, A. Tokar, Thin Solid Films, 450 (2004) 8489.

[18] C. Wyon, J.P. Gonchond, D. Delille, A. Michallet, J.C. Royer, L. Kwakman, S. Marthon, Applied Surface Science, 253 (2006) 21-27.

[19] M.A. Sapia, J.G. Clark, in, Google Patents, 1991.

[20] G.J. Lamont, D.P. Wilkinson, in, Google Patents, 2003.

[21] M. Boehmisch, C. Haas, in, Google Patents, 2006.

[22] N.V. Aieta, P.K. Das, A. Perdue, G. Bender, A.M. Herring, A.Z. Weber, M.J. Ulsh, Journal of Power Sources, 211 (2012) 4-11.

[23] P.K. Das, A.Z. Weber, G. Bender, A. Manak, D. Bittinat, A.M. Herring, M. Ulsh, Journal of Power Sources, 261 (2014) 401-411.

[24] D.C. Bittinat, G. Bender, J.M. Porter, M. Ulsh, ECS Transactions, 58 (2013) 495-503.

[25] M. Ulsh, Porter, J.M., Bittinat, D.C., Bender, G., Fuel Cells, 16 (2015) 170-178.

[26] T. Berning, D.M. Lu, N. Djilali, Journal of Power Sources, 106 (2002) 284-294.

[27] T. Mitani, F.A. Williams, Combustion and Flame, 39 (1980) 169-190.

[28] M.D. Deshpande, R.N. Vaishnav, Journal of Fluid Mechanics, 114 (1982) 213-236.

[29] G.S. Hwang, A.Z. Weber, Journal of the Electrochemical Society, 159 (2012) F683-F692. 
[30] M. Glauert, Journal of Fluid Mechanics, 1 (1956) 625-643. 